\title{
"Dual Decoding" of Graphic Design Language
}

\author{
Hualiang Wu \\ Information and Network Administrative Center, Jiangxi University of Technology, Nanchang 330029, \\ Jiangxi, China
}

Keywords: Graphic Design Language; Dual Decoding; Self-regulation of artistic

\begin{abstract}
The dual decoding is a creative approach breeding from post-modern design. Graphic design "double coding" is the combination of traditional design elements and modern design elements and it draws nourishment and stimulates creative inspiration from different cultures. The works created by eclectic method with diversified design trend, often seem vivid and lively. Comparing with the works created by modernist graphic design using points, lines, surfaces and colors, the works have more cultural heritage and historical connotations.
\end{abstract}

\section{Introduction}

Self-regulation of artistic development includes two aspects: First, from the longitudinal development of the arts, the artistic development of yesterday, today and tomorrow have inevitable, essential, stable contact, which is the inheritance and innovation of arts development; second, from the aspect of art horizontal linkage, the inevitable, natural and stable connection between different ethnic arts, national arts and global arts, which is the reference and creation of multi-ethnic arts, and the interaction and integration of ethnic art and global arts.

Marx said that people make their own history, but they are not free to create history, or create it in their self-selected circumstances, but directly encountered, given, inherited from the past to create the history. One of dual decoding methods is to perform eclectic processing of native culture and foreign cultures, to achieve mixing "exotic hybrid", "dances with wolves." This eclectic method is based on the nation's cultural style and absorbs the factors of extraterritorial works that are suitable for presenting the subject, so that the works show open mind and mixing momentum, both with local characteristics and with the time and worldwide.

Combination of traditional design elements and modern graphic design. Fine cultural tradition is the correct manner of human cultural activities selected by history. Design is inseparable from culture and tradition and is never purely personal behavior that can do arbitrarily. Traditional penetrates in any design environment and any designer's inner world.

As an integral part of human culture, graphic design has no exception and unbreakable blood contact with traditional culture. It can be seen that a lot of examples of outstanding works are created by combining traditional elements with modern design factors in the graphic design. Many carefully try to figure out and browse some contemporary graphic design works. These works utilize traditional design elements in modern design flexibly, not only embodying the concept of modern graphic design and fashion, but also reflecting the characteristics of national culture and aesthetic orientation, showing the artistic charm through compromises and cohesive connection of traditional design elements and modern visual language. Traditional and modern combination does not only have external form of stitching, but also has intrinsic spirit coinciding. The traditional design 
elements used in modern graphic design do not only include nationalization graphics with distinct characteristics, traditional calligraphy and painting, such as traditional decorative patterns, motifs and calligraphy and painting and other material, including traditional artifacts, supplies, construction, etc. which have three-dimensional rendering state and typical images, as well as traditional style charm. Once these images are applied to graphic design, they will have rich tradition meanings. For example, some graphic design works use bronze, jade, ancient sculptures and other images.

China's traditional graphical modeling pays attention to the intensional mood. Li Zehou said in Miscellaneous Discussions of "Mood', "mood" is the integration of "love", "reason", "form" and "spirit", and the unity of objective scenery and subjective interest. Form and spirit are the premise of mood creation; form means graphics, referring to the visual image of art, which is the carrier of mood generation. "Spirit" refers to the artistic spirit in the higher realm. Integrating subtle beauty into the mood is a goal always pursued by Chinese traditional plastic arts. The pursuit and performance of mood by traditional artistic language is one of the reasons with charm. Chinese traditional ink painting is the greatest in pursuing mood creation. In modern graphic design, there are a lot of works of the combination of traditional ink painting and modern design integration.

Chinese traditional ink painting focuses "lively". An art theorist of Wei, Jin, Southern and Northern Dynasties Xie He put forward the standards to evaluate painting quality in his painting theoretical works Ancient Paintings Recorded, that is "six items", in which "lively" was taken as the primary standard. In some ways, modern graphic design should also take this standard as the benchmark, focusing on creating graphics artistic. The sign of Beijing's Olympic bid is an example taking traditional "Chinese knot" as the basic creative material with artistic conception. Through elaborate design of graphics and color, the designer uses ingenious and refines traditional graphics in modern visual design, making the ideological mood represented by the logo art wander out of things. The logo is like a human playing Taichi, and its simple dynamic lines symbolize grace, harmony and strength. The designer rotates Olympic rings for $45^{\circ}$, interpreting as a five-pointed star with considerable momentum, and it also has the same structure with Chinese traditional folk craft "Chinese knot" to form a chain, reflecting the Chinese people working together to expect the Olympic Games, as well as symbolizing the unity, cooperation and exchanges between the people of the world. In the design techniques, the modeling logo adopts the oriental calligraphy, with lines flying lines and connected meaning, to give unlimited imagination and inspire people to pay attention to China.

Our life is based on the history of previous creation, whether it is the basic necessities of material or spiritual literature and art, continuing to move forward on the basis of inheriting the historical creative achievements of our ancestors. People cannot get rid of the history, and culture creation is not only in real-life scenarios, but also in history and given culture scenarios. No matter the rebellion or creative development of tradition, it's a cultural activity based on certain history.

So is the design, as a thing connecting people's daily lives closely. In the context of contemporary culture, how to transfer the outstanding factors of traditional culture into new design vocabulary and give more contemporary design with rich cultural heritage, "double decoding" provides us with a viable approach - history compromise, to combine the outstanding cultural factors with modern design and propose to use both the tradition and the modern time. It speaks with the tradition under new cultural scene, and makes traditional culture and modern aesthetics communicate, learning positive factors traditional culture to create selectively and adding a richer form vocabulary and culture connotation for contemporary design. In modern design, taking traditional symbols as 
creative elements can deliver the visual information with national cultural image in the completion of design theme simultaneously, forming visual image of personality and culture, which is incomparable for geometric graphic, points, lines and surfaces. In the exchange of international design culture, these design works having traditional design elements and national culture can show the unique charm of Chinese culture.

Dual decoding focuses the importance of design historical context, and advocates learning from tradition, absorbing nutrients from the traditional culture. Being keen on historical context and making deconstruction, it completes sorting out history and traditional inheritance in a special way-compromise. It can be known from the previous section that one of dual decoding compromise performance is connecting traditional and modern design elements, merging traditional elegance and modern novel. It does not only have historical element, but also has a sense of the times. Taking both tradition and age into account, double decoding works not only connect history, but own longer history. Creation personality is not lost, only to find new inspiration in the traditional vocabulary. Dual decoding is affirmation and reference of historical elements, and its approach is to re-interpret and re-use traditional design material and historical vocabulary, showing design idea expansion and design presentation exploration in the course of using.

\section{The beauty of neutralization}

Neutralization is an important area of the history of thought and cultural history in ancient China,. In literary field, neutralization is usually called the beauty of neutralization. It is a universal art concept of harmony containing dialectical spirit. As an aesthetic principle, it pays attentions to that the coexistence, mutual complement and coordination of all reasonable factors, styles, constituting a dynamic and harmonious system. The ethnic characteristics of Chinese culture can be summarized as "reconciling and maintaining the middle", which is mainly influenced by Confucius' "moderate" ideology, which is the so-called "Yong, use it." (Zheng Xuan: Book of Rites, Doctrine of the Mean) "Doctrine of the Mean" means "used the mean", and its full expression is "dual enforcement, mean use", which means to master the opposite ends and choose and use the correct point between the two ends.

Confucius said that for ritual purpose, harmony is the most previous", "harmony" is the core of Confucius Aesthetics, and is also what the "Doctrine of Mean" advocates. "Harmony" refers to the equal coexistence and mastery among different elements. What the realm that beauty of neutralization pursuing is to mix the different internal factors according to the proportion of "mean" and reach the final of harmony.

The ancient people got intuitive feel of beauty from the diversity of things. They thought that beauty was born in the harmony of various things in the universe. Unification of different things constitutes the natural life and may produce something new. Repeating the same thing cannot produce new things, and natural life will be difficult to continue.

This idea is in line with the laws of nature, which also has an important guiding significance for the art. Another meaning of "neutralization" is to emphasize the balance, harmony and unity of a variety of different things and relationships. The factors entering neutralization, whether the same, or diverse, are interdependent, in the principle of unity, experiencing mutual permeability blending and complementary alternate motion. Because many factors are varying but harmonious and orderly movement, which generates continuous harmonious body and harmonious system. 


\section{Resource fusion at all times and in all over the world}

Facing with abundant ancient and modern design resources, dual decoding accommodates them together by compromise to make them generate organic integration, which does not only reflect the appearance, but also reflects the spirit in the inner. It is the compromise of traditional design idea and modern design concept, as well as the aesthetic compromise of East-West design. In the design idea, Chinese art design doesn't praise logical thinking, focusing on the image and figurative form with perception, to take the thinking of themselves as the center for the overall perception of objective objects, such as China's traditional graphics are summarized based on the sketch of natural image change. Westerners praise logical thinking and inductive method highly, focusing on creative thinking. The fundamental purpose is to seek knowledge, to study the root and seek the source. The spreading and strict rational way of thinking makes western design works full of Western realism freedom and individual consciousness. Chinese traditional designs focus on holistic, harmonious and transformation ways of thinking. The ancient Yin and Yang rotation in Tai-chi figure, group-like, suit pattern in traditional patterns all reflect the essence of this way of thinking. Chinese traditional design thinking focuses the accumulation of personal experience, nature obedience, natural thing, and the pursuit of harmony between human and nature in the design. And Western art design thinking focuses the guidance of scientific design theory, paying more attention to design science, emphasizing the conceptualized aesthetic laws in the design application and focusing on the design of standardization. Chinese art and design thinking have planarity characteristics, paying attention to abstract planarity of color and shape. Such as paper-cut art takes 2D space concept the basis of imaginal thinking, and things images in the author's eyes have become silhouette style image with no volume, no space, no stress on "near big, the far smaller" perspective ratio. The infinite space is "flattened" on a plane. Western art design thinking focuses on three-dimensional effect. With respect to the West, China is conservative and not easy to accept new ideas, so new things grow requires a long process. The Western design thinking is open and inclusive, and different and even opposing views can be respected and accepted. Therefore, their ability to accept new things is strong, with strong pioneering and innovative spirit.

A prominent feature of western aesthetics is "individual beauty," focusing the image of art works and playing an active role better in the environment. The ancient must be changed to track the time, removing the chaff. With the changing times, as a visual image resource, the traditional cultural symbols cannot revel in the original form beauty any more. The new visual culture requires a new form of re-interpretation of their ancient beauty and wisdom.

This new interpretation is to reconstruct new visual identity based on traditional visual graphic symbols while retaining its cultural implications. This reconstruction is not a simple ism, but reconstructs on the basis of the existing design elements to break up in accordance with new aesthetic requirements and composition rules; it is a re-creation process, a kind of orderly, harmonious and overall construction. In accordance with the new aesthetic values, these East and West, old and new elements are reassembled into new visual identity, giving new form and content according to new aesthetic value orientation under the requirements of modern graphic art design constitute laws and the care of artists. 


\section{Conclusion}

Dual decoding usage in modern graphic design mainly embodies the combination of traditional elements with modern visual language and design elements as well as the organic blend of different national cultures. Chinese traditional culture is the source of modern art design. The design cannot put aside the accumulated history, so that the compromise of tradition and modern time based on inheriting the tradition; at the same time, in the face of strong local culture of Chinese nation, ferocious West is selected and transformed in a certain degree, forming the lateral compromise between Western and Eastern. The longitudinal compromise in graphic design is the intersection, collision and fusion of past design elements and present graphic design concept, and the designers make coordination and balance between new and old, traditional and modern compromise model, to form visual conveying art involving the essence of traditional culture and modern design features. Lateral compromise between Western and Eastern design elements are to reconstruct and combine several design elements through certain design methods according to modern design aesthetic requirements in the premise of in-depth grasping. The creative approach with compromise of various design elements is used widely in modern design with various forms, and there are many topics to be studied. In this paper, the compromise phenomenon of traditional and modern, as well as different cultural elements in graphic design field is discussed here. The author hopes the present knowledge is useful to contemporary graphic design and creates some inspiration.

\section{Acknowledgment}

This work was supported by Natural Science Foundation of Jiangxi Province [No 20142BAB207008] and project of Science and Technology Department of Jiangxi Province [No 2013BBE50051]. The authors thank Wang Ping for technique support.

\section{References}

[1] Roth S F, Kolojejchick J, Mattis J, et al. Interactive graphic design using automatic presentation knowledge[C]//Proceedings of the SIGCHI conference on Human factors in computing systems. ACM, 1994: 112-117.

[2] Feiler P H, Gluch D P, Hudak J J. The architecture analysis \& design language (AADL): An introduction[R]. Carnegie-Mellon Univ Pittsburgh PA Software Engineering Inst, 2006.

[3] Fei G U O. Artistic Conception of Graphic Language[J]. Packaging Engineering, 2007, 12: 075.

[4] Calori C, Chermayeff I. Signage and wayfinding design: a complete guide to creating environmental graphic design systems[M]. Hoboken, NJ: Wiley, 2007.

[5] Duley J R, Dietmeyer D L. A digital system design language (DDL)[J]. Computers, IEEE Transactions on, 1968, 100(9): 850-861.

[6] Casner S M. Task-analytic approach to the automated design of graphic presentations[J]. ACM Transactions on Graphics (TOG), 1991, 10(2): 111-151.

[7] Baron N S. Computer mediated communication as a force in language change[J]. Visible language, 1984, 18(2): 118-141.

[8] Kosslyn S M, Cunningham D H. Elements of graph design[M]. New York: WH Freeman, 1994. 
[9] Twyman M. A schema for the study of graphic language (tutorial paper)[M]//Processing of visible language. Springer US, 1979: 117-150.

[10] Mackinlay J. Automating the design of graphical presentations of relational information[J]. Acm Transactions On Graphics (Tog), 1986, 5(2): 110-141. 